EXTENDED REPORT

\title{
Severe disease in patients with rheumatoid arthritis carrying a mutation in the Mediterranean fever gene
}

\author{
E Rabinovich, A Livneh, P Langevitz, N Brezniak, E Shinar, M Pras, Y Shinar
}

Ann Rheum Dis 2005;64:1009-1014. doi: 10.1136/ard.2004.029447

See end of article for authors' affiliations

Correspondence to

Correspondence to:
Dr Y Shinar, Heller Institute

of Medical Research,

Sheba Medical Centre,

Tel Hashomer 52621

Israel; yshinar@

sheba.health.gov.il

Accepted

28 December 2004

Background: Pyrin is a newly recognised intracellular regulator of inflammation, and mutations in MEFV, the gene encoding pyrin, are the cause of familial Mediterranean fever.

Objective: To determine if known mutations of MEFV are associated with rheumatoid arthritis (RA) morbidity or can modify RA severity.

Methods: The frequency of the three most common MEFV mutations: M694V, V726A, and E148Q, was determined in 98 Israeli patients with RA (74 women, 24 men) and compared with that in 100 healthy subjects matched for origin. RA severity was determined using a new clinical score of 126 grades. The median severity score of mutation carrier and non-carrier groups was compared after confounding measures were eliminated by logistic regression.

Results: 17/98 (17\%) patients with RA (all women) were heterozygous for common MEFV mutations, predominantly E148Q (12 patients), and one patient was homozygous for the V726A mutation. The overall mutation rate was comparable between patients with RA and healthy subjects. Patients carrying a mutation had a higher median severity score than the non-carrier group (42 v 29, $p=0.0005$ ). The logistic regression model assigned a 15 -fold odds ratio for severe RA in carriers, after adjusting for sex, presence of rheumatoid factor, age at onset, and disease duration ( $n=97, p=0.01,95 \% \mathrm{Cl} 1.74$ to 128).

Conclusion: MEFV, and particularly the El48Q mutation, is an independent modifier of the clinical manifestations of RA. This is the second Th1-type autoimmune disease in which MEFV mutations have been shown to aggravate the clinical status.

$\mathrm{R}$ heumatoid arthritis (RA (MIM180300)) is a systemic autoimmune disease primarily affecting the joints, and present in about $0.8 \%$ of the world population. The risk of developing RA is ascribed in part to genetic factors, which, besides the important HLA class II DRBl gene, encoding the consensus, high risk amino acid sequence QKRAA or related sequences, ${ }^{1-3}$ include less well characterised susceptibility intervals on chromosomes $1,6,12,16,17,18$, and $21^{4-6}$ Moreover, additional immune system genes may affect RA manifestations. For instance, the variable extent of joint erosions among patients ${ }^{78}$ has been related to the DR antigens, ${ }^{9}$ rheumatoid factor (RF), ${ }^{10}$ and to several gene variants of the innate immune system. ${ }^{12-14}$ RA development and expression may therefore be associated with heterogeneous predisposing gene combinations, and with additional, as yet unidentified, loci.

Pyrin and several other proteins containing the pyrin domain are intracellular modules of inflammatory signalling that are associated with autoinflammatory disorders. ${ }^{15}$ Mutations in $M E F V$, the gene encoding for pyrin, cause familial Mediterranean fever (FMF), a recessive recurrent polyserositis $^{1617}$ and are associated to a lesser extent with several other autoinflammatory conditions. ${ }^{18-22}$ When combined with a Thl related autoimmune disease, carrying an $M E F V$ mutation may aggravate the disease course, as shown for carriers among patients with multiple sclerosis of nonAshkenazi origin. ${ }^{23}$

A connection between $M E F V$ mutations and arthritic diseases was suggested by Booth et al, who found that the E148Q mutation was overrepresented in white and Indian patients with inflammatory arthritis and amyloidosis. ${ }^{24} \mathrm{~A}$ recent report extended this association and showed overrepresentation of the $\mathrm{M} 694 \mathrm{~V}$ mutation in a cohort with juvenile RA. ${ }^{25}$ Interestingly, arthritis is a common manifestation in FMF, especially in M694V homozygotes. ${ }^{26-30}$ Moreover,

monocytes and synovial fibroblasts have been reported to express $M E F V$ in culture. ${ }^{31} 32$

Because $M E F V$ mutations are carried by $10-20 \%$ of the general population amongst Semite people (see, for example, Stoffman $e t a l^{33}$ ) it is important to investigate the impact of this genotype on RA.

We adopted a case-control design, to compare the $M E F V$ mutation frequency between patients with RA and healthy subjects, and to compare disease severity between mutation carriers and non-carriers, as this design is considered the most sensitive method of identifying disease risk factors in a small sample. ${ }^{34}$

\section{PATIENTS AND METHODS}

\section{Patients and healthy subjects}

The study included 98 patients with RA (74 women, 24 men), recruited consecutively and followed up at the rheumatology clinic of Sheba Medical Centre, Tel Hashomer, Israel. All patients fulfilled the American College of Rheumatology criteria for diagnosis of RA..$^{35}$ The median duration of RA in the entire cohort was 11 years, and the median onset was at 47 years of age. One hundred healthy blood donors (67 men, 33 women), serving as controls, were recruited consecutively at the National Blood Services donation centre, at TelHashomer, Israel. An attempt was made to match the ethnic composition of the healthy group to that of the patients with RA. There were two exceptions to this, Iraqi-Jewish patients were overrepresented in the RA group $(14 \vee 3, p=0.03)$ and Yemenite-Jewish patients were overrepresented in the healthy subject group ( $3 \vee \mathrm{l}, \mathrm{p}=0.05)$. In addition, the healthy blood donors completed a questionnaire inquiring about FMF, RA, or other autoinflammatory or autoimmune

Abbreviations: $\mathrm{Cl}$, confidence interval; FMF, familial Mediterranean fever; IL, interleukin; RA, rheumatoid arthritis; RF, rheumatoid factor 
Table 1 Score system for RA severity

\begin{tabular}{|c|c|c|}
\hline Parameter & Method of scoring & Maximal score* \\
\hline Tender or swollen joints & 1 for each inflamed joint & $\begin{array}{l}\text { Upper limbs } 10 \\
\text { Lower limbs } 10\end{array}$ \\
\hline Deformed joints & 1 for each joint & $\begin{array}{l}\text { Upper limbs } 10 \\
\text { Lower limbs } 10\end{array}$ \\
\hline Joint disability affecting daily tasks $\dagger$ & $\begin{array}{l}5 \text { when affecting complex movement in an } \\
\text { independent subject } \\
10 \text { when subject needs help in eating and } \\
\text { dressing } \\
15 \text { when subject totally depends on assistance } \\
5 \text { when walking with a cane } \\
10 \text { when using a walker } \\
15 \text { when using a wheelchair or bed-ridden }\end{array}$ & $\begin{array}{l}\text { Upper limbs } 15 \\
\text { Lower limbs } 15\end{array}$ \\
\hline Extra-articular, RA related disease $\dagger$ & & Lower limbs \\
\hline Neurological & 2.5 for each affected limb & 10 \\
\hline Respiratory & $\begin{array}{l}2 \text { for shortage of breath during effort } \\
4 \text { for shortage of breath at rest } \\
6 \text { for need of oxygen }\end{array}$ & 6 \\
\hline $\begin{array}{l}\text { Heart insufficiency } \\
\text { Amyloidosis/vasculitis }\end{array}$ & $\begin{array}{l}2.5 \text { for each level according to AHA } \\
2 \text { for each affected organ/limb }\end{array}$ & $\begin{array}{l}10 \\
10\end{array}$ \\
\hline Drug load & 1 for each RA intended drug & 10 \\
\hline Unresponsiveness to treatment & $\begin{array}{l}1 \text { for each month of current year with acute } \\
\text { symptoms }\end{array}$ & 10 \\
\hline Total for all measures & & 126 \\
\hline
\end{tabular}

diseases, and reported none. All participants, patients and healthy subjects, consented to the study in writing and donated $2 \mathrm{ml}$ of blood, collected in an EDTA tube.

\section{Detection of common MEFV mutations}

Genomic DNA was prepared from $200 \mu \mathrm{l}$ of whole blood using a commercial kit (high template polymerase chain reaction preparation kit, Roche IL, USA). Three common MEFV mutations-M694V, V726A, and E148Q-identify 70\% of the FMF chromosomes in Israeli-Jewish patients with FMF. These mutations were detected on polymerase chain reaction amplified fragments of exon 10 and exon 2 of $M E F V$ by enzymatic restriction analysis as previously described. ${ }^{36}$

\section{RA severity score: content, applicability, and construct validation}

All patients were examined, interviewed, and then scored once during the year 2000. Table l describes the new scoring system. It grades RA manifestations according to the extent of disease, organ dysfunction, disability, and suffering. It is simple and does not require an expert opinion other than that of a rheumatologist, it only minimally depends on the patient's or physician's perception of the severity of the disease, and there is no prerequisite for laboratory investigation. It was developed in the absence of a composite scoring system for RA, and the growing use of a combination of complementary scoring systems, each evaluating one aspect

Table 2 Rate of MEFV mutations in 98 Israeli patients with RA and 100 healthy subjects

\begin{tabular}{llll}
\hline Mutation & $\begin{array}{l}\text { Patients with RA } \\
\text { No (frequency) }\end{array}$ & $\begin{array}{l}\text { Healthy subjects } \\
\text { No (frequency) }\end{array}$ & $\begin{array}{l}\mathbf{p}^{2} \text { Value for } \\
\chi^{2}\end{array}$ \\
\hline E148Q & $12(0.06)$ & $6(0.03)$ & 0.13 \\
M694V & $4(0.02)$ & $3(0.015)$ & \\
V726A & $3(0.015)$ & $3(0.015)$ & \\
Total rate & $19(0.095)$ & $12(0.06)$ & 0.17 \\
\hline
\end{tabular}

One patient with RA was homozygous for the V726A mutation and one healthy subject was compound heterozygous for the V726A and 148Q mutations. Neither had FMF. of disease activity (for example, Sharp or Larsen scores to evaluate joint destruction, RA Disease Activity Index (RADAI) or Disease Activity Score (DAS) scores to assess disease activity, and Health Assessment Questionnaire (HAQ) score to measure health status). Validation of the present scoring system was obtained by correlating its outcome with the presence of the RF, a known, external marker of RA severity.

\section{Rheumatoid factor}

Patients whose plasma contained high titre (1/20 or higher) IgM antibodies capable of aggregating IgG coated latex beads were considered RF positive.

\section{Statistical analyses}

The rate of $M E F V$ mutations, $\mathrm{n} / 2 \mathrm{~N}$, is the number of mutations (n) in the $M E F V$ genes of $\mathrm{N}$ screened subjects. This rate was compared between RA and healthy cohorts by Fisher's exact test. The RA severity score is non-parametric (disability is not a continuous variable) and therefore the medians of the total score and of the disability score were compared between groups using the Mann-Whitney test. The statistical significance of all other score differences was assessed by Student's $t$ test. A multiple logistic regression model was used to determine the independent effect of five variables (carrier status, female sex, RF, age at onset, and disease duration) on the risk of scoring above median severity. Differences were considered significant when the probability that they occurred by chance was $<0.05$. These analyses were performed using SAS software (SAS Institute, Cary, North Carolina).

\section{RESULTS}

\section{MEFV mutation frequency in patients with RA}

A screen of 98 patients with RA for common mutations identified 17 heterozygous and one homozygous patient with no FMF manifestations (V726A/V726A), and an overall mutation rate of 0.095 . A comparable mutation rate (0.06) was found in the healthy cohort of 100 blood donors of matched ethnic composition recruited for this study 


\begin{tabular}{|c|c|c|c|c|c|}
\hline & Carriers & $95 \% \mathrm{Cl}$ & $\begin{array}{l}\text { Non- } \\
\text { carriers }\end{array}$ & $95 \% \mathrm{Cl}$ & $\mathrm{p}$ Value \\
\hline Number of patients (n) & 18 & & 80 & & \\
\hline Mean age at onset of RA (years) & $54.3^{*}$ & 48.9 to 59.7 & 45.9 & 41.8 to 49.9 & 0.07 \\
\hline Mean age at diagnosis (years) & 56.8 & 50.4 to 63.1 & 46.9 & 42.7 to 51.0 & 0.07 \\
\hline RA duration (years) & $10.9^{\star}$ & 7.9 to 13.8 & 15.0 & 12.7 to 17.3 & 0.1 \\
\hline Women, No (\%) & $18(100)$ & & $56(70)$ & & 0.01 \\
\hline Familial RA, No (\%) & $2(11)$ & & $10(13)$ & & 1 \\
\hline Ashkenazi patients, No (\%) & $8(44)$ & & $37(46)$ & & 0.9 \\
\hline Non-Ashkenazi-Jewish, No (\%) & $9(50)$ & & $37(46)$ & & 1.0 \\
\hline Others $\dagger$ & $1(6)$ & & $6(8)$ & & \\
\hline RF positive patients, No (\%) & $17(94)$ & & $42(53)$ & & 0.001 \\
\hline \multicolumn{6}{|c|}{$\begin{array}{l}95 \% \mathrm{Cl} \text {, confidence interval for the mean when } \alpha=0.05 \text {. } \\
\text { "The age at onset of RA was unavailable for one carrier patient, } \mathrm{n}=17 \text {. } \\
\text { The "Others" group had one Arab carrier patient, two non-carrier patients of mixed (Ashkenazi and non- } \\
\text { Ashkenazi) origin and four non-carrier patients of undetermined Jewish ethnicity. For the entire ethnic distribution } \\
\text { of carriers and non-carriers, } \mathrm{p}=0.9 \text {. }\end{array}$} \\
\hline
\end{tabular}

$(\mathrm{p}=0.17$, table 2); Omitting the Iraqi-Jewish and YemeniteJewish patients, whose frequency was unequally distributed between the patients and control groups (as specified in the "Patients and methods" section) had little effect on the overall mutation rate in either cohort $(0.085 v 0.07, \mathrm{p}=0.4)$. All mutation carriers in the RA cohort were women (17/74 female carriers $v 0 / 24$ male carriers, $p=0.009$ ), whereas mutation carriers in the healthy cohort were distributed among men and women (5/33 female carriers $v 6 / 67$ male carriers, $\mathrm{p}=0.3$ ).

Table 3 presents the clinical and demographic characteristics of the carrier patients. Carriers had a later mean onset of RA of about 8 years $(p=0.07)$ and later diagnosis of RA of about 10 years $(p=0.07)$ than non-carriers, and correspondingly, a shorter mean disease duration (10.9 years in carriers $v 15.0$ years in non-carriers, $\mathrm{p}=0.1$ ). The ethnic composition and rate of familial RA were comparable in both subgroups.

\section{Severity score}

The severity score of patients with RA ranged between 6 and 70 out of a maximum score of 126 , and was distributed with a median of 34 (fig 1A). The severity score outcome was validated against the presence of RF, an accepted severity risk factor. Forty of the 59 RF positive subjects had a higher than median severity score (sensitivity $=68 \%$, 95\% confidence interval (CI) 0.55 to 0.78 ), whereas $30 / 39$ RF negative patients scored below or equal to the median severity score ( specificity $=77 \%, 95 \%$ CI 0.62 to 0.87 ). A small increase in sensitivity $(71 \%, 95 \%$ CI 0.53 to 0.85$)$ was obtained when only quartiles 1 and 4 of the severity chart were considered. The positive predicted value of the score (the fraction of RF positive patients among those with a score above the median) was 0.82 (95\% CI 0.7 to 0.9 , diagnostic odds ratio $(\mathrm{OR})=7.0$, $95 \%$ CI 2.7 to $17.7, \mathrm{p}<0.0001)$.

\section{Severity score in MEFV mutation carriers}

The median score of patients who carried a common $M E F V$ mutation was higher than that of non-carriers by 13 grades: $42 \vee 29$ respectively $(\mathrm{p}=0.0005$, fig $1 \mathrm{~B})$. Carriers of the E148Q mutation alone $(n=12)$ had a significantly higher median score than non-carriers ( $46 v 29, \mathrm{p}=0.0015$, data not shown graphically). The measures that scored significantly higher in carriers were count of deformed joints, disability, extra-articular manifestations, drug load, and the duration of active disease despite treatment in the past year (table 4). Notably, vasculitis was as prevalent in carriers as in noncarriers $(3 / 18 v 13 / 80, \mathrm{p}=1)$, only one patient (a non-carrier) had amyloidosis, and yet severe heart insufficiency and respiratory complications were overrepresented among the carrier patients $(3 / 18 v 1 / 80$, respectively, $\mathrm{p}=0.02)$.

Because all carrier patients were women, sex was analysed as a confounding factor for increased severity. Indeed the median score of women of the entire RA cohort was higher than that of the men ( $36 v 24$ respectively, $\mathrm{p}=0.002$, fig $1 \mathrm{C}$ ). Nevertheless, female carriers $(n=18)$ had a higher median score than female non-carriers $(\mathrm{n}=56)(42 v 33$, respectively, $\mathrm{p}=0.004$, fig lD).

As expected RF positive patients $(n=59)$ had a higher median severity score than RF negative patients with RA $(\mathrm{n}=39)$ by 10 grades $(\mathrm{p}=0.01$, fig $\mathrm{IE})$, and a higher score in each score variable $(\mathrm{p}<0.05)$. Because almost all $M E F V$ mutation carrier patients (17/18), but only 42/80 (53\%) noncarriers tested positive for RF, the effect of $M E F V$ mutations was also analysed separately in RF positive patients. In this cohort the median score of mutation carriers still remained higher than that of non-carriers by 11 grades (45 $v$ 34, respectively, $p=0.006$, fig $1 F$ ).

Finally, in comparison with female non-carriers who were also RF positive $(n=32)$ the corresponding carriers $(n=17)$ still had a higher median severity score by 9 grades ( $45 v 37$, $\mathrm{p}=0.03$, not shown graphically).

The effect of $M E F V$ mutations on RA severity was also determined using a multiple logistic regression model with five variables and a dichotomous outcome (score above the median $=1$, score equal to or below the median $=0$ ). When the age at onset, disease duration, sex, and RF were adjusted between the carrier and non-carrier groups the presence of a mutation predicted a 15 -fold odds ratio to score above median severity $(\mathrm{n}=97,95 \%$ CI 1.7 to $128, \mathrm{p}=0.01)$. Similarly, after adjustment of the age at onset, disease duration, sex, and mutation status between the RF negative and positive groups the presence of the RF predicted a 3.0fold odds ratio to score above the median (95\% CI 1.1 to 7.9 , $\mathrm{p}=0.02$ ). The age at onset and sex of the subject had no significant effect on severity $(p=0.9$ and $p=0.5$, respectively). Disease duration had a negligible effect on the severity outcome in the model $(\mathrm{OR}=0.99,95 \%$ CI 0.9 to $\mathrm{l}$, $p=0.07)$. All in all, there was a good fit between the dichotomous outcome predicted by the five variables combined and the observed severity score of the patient ( $\mathrm{c}=0.80$, likelihood ratio $=30.2, \mathrm{df}=5, \mathrm{p}=0.0001$ ).

\section{DISCUSSION}

This study suggests a strong association between RA severity and the presence of mutations in the $M E F V$ gene in patients with RA. The association was found using a new, integrative, and comprehensive clinical scoring system assessing disease 

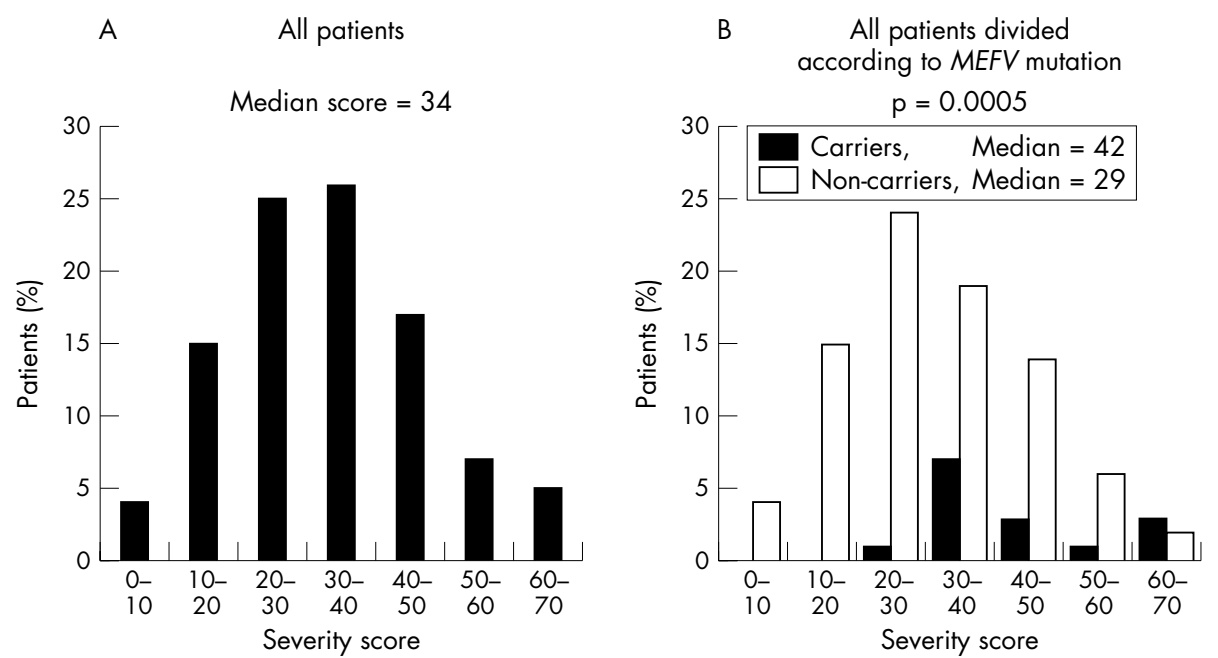

C Male and female patients
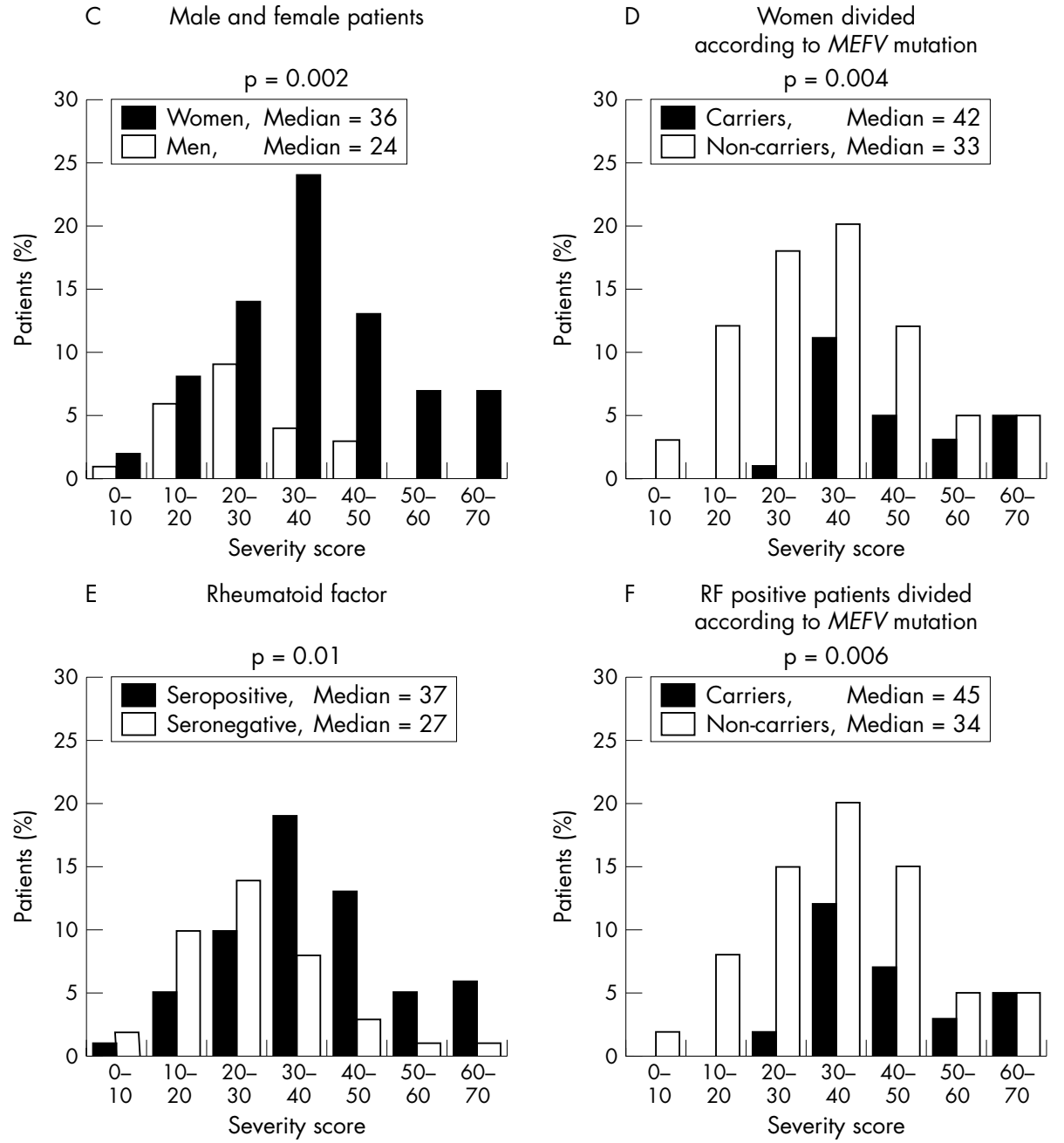

Figure 1 The severity score of patients with RA. The score range was divided into grade intervals of 10 and the score of each patient distributed to the appropriate interval. (A) Score distribution of all patients. (B) Patients with or without MEFV mutations. (C) Female or male patients. (D) Female patients with or without MEFV mutations. (E) RF positive or negative patients. (F) RF positive patients with or without MEFV mutations.

activity, suffering, extent of joint and organ involvement, and physical disability by using measurable and comparable criteria. This scoring system yielded a wide range of values with a Gaussian distribution for all patients. The scoring system was validated by correlating its outcome with two known predictors of RA severity. Specifically, women had a higher median score than men and RF positive patients had a higher score than RF negative patients when assessed with this system. Carriers of the $M E F V$ mutations maintained a higher median score than non-carriers when these confounding factors were eliminated using a multiple logistic regression model. The adjusted odds ratio for severe RA in carriers was five times higher than that associated with the $\mathrm{RF}$, suggesting that disease-causing alleles in $M E F V$ are 
Table 4 Mean score in each severity variable in relation to the MEFV genotype

\begin{tabular}{llll}
\hline Variable & $\begin{array}{l}\text { Carriers } \\
(\mathbf{n}=18)\end{array}$ & $\begin{array}{l}\text { Non-carriers } \\
(\mathbf{n}=80)\end{array}$ & $\mathrm{p}$ Value \\
\hline Tender or swollen joints & $8.9(5.2)$ & $7.5(5.8)$ & 0.38 \\
Deformed joints & $10.1(6.9)$ & $6.9(5.9)$ & 0.04 \\
Disability in daily tasks* & 10 & 5 & 0.06 \\
Extra-articular manifestations & $2.4(5)$ & $0.6(1.4)$ & 0.006 \\
Drug load & $5.8(1.9)$ & $4.5(2.1)$ & 0.01 \\
Active disease in past year & $8.5(2)$ & $5.8(2)$ & 0.001 \\
Total score* & 42 & 29 & 0.001 \\
\hline *Median score, because the variable is non-continuous. \\
\hline \multicolumn{4}{l}{} \\
\hline
\end{tabular}

independent and major genetic aggravating factors for RA severity. It is noteworthy that preliminary data showed no association between joint disease and the HLA-DRBl typing in patients with FMF (Shinar et al, unpublished data).

Interestingly, $M E F V$ maps within a susceptibility region for RA on chromosome 16p13-q12.2 that has emerged with recent meta-analysis of four separate genome screens. ${ }^{537}$ How mutations in $M E F V$ might increase the severity of RA is not yet known, but this may be related to the function of pyrin. This molecule is a cytoplasmatic protein with an $\mathrm{N}$ terminal domain related by secondary structure to the death domain of transducers of apoptotic and inflammatory signals. ${ }^{38}$ Pyrin regulates the rate of pro-interleukin (IL) $1 \beta$ processing to IL1 $\beta$ by caspase- 1 via binding to apoptotic speck protein (ASC), a protein containing a procaspase-1 recruiting domain. ${ }^{39}{ }^{40}$ Germ line disruption of pyrin in mice resulted in increased IL1 $\beta$ secretion by peritoneal macrophages in culture, in response to lipopolysaccharide. ${ }^{41}$ Possibly, a similar increase in ILl $\beta$ secretion occurs in response to proinflammatory proteins in patients with RA who express a mutated form of pyrin. This cytokine is pivotal in inducing clinical manifestations of $\mathrm{RA}^{42}$ and the recombinant ILl receptor antagonist, anakinra (Kineret), is effective in treating patients with RA and reducing joint destruction. ${ }^{43}$ An increase in ILl that is driven by mutated pyrin may therefore exacerbate RA. Also of note is the finding that healthy heterozygotes for $M E F V$ mutations appear to have higher than normal blood levels of acute phase reactants, ${ }^{44}$ supporting the role of $M E F V$ mutation in the induction of inflammation.

FMF is described as an autoinflammatory disease as it is not thought to be driven by defects in the adaptive immune response. It is therefore interesting that this is the second study in which FMF-causing mutations in $M E F V$ have been found to be associated with increased severity of an autoimmune disease. In a previous study of a Jewish cohort with multiple sclerosis increasing disability occurred more rapidly in patients carrying the $M 694 \mathrm{~V}$ allele of $M E F V .^{23}$ Interestingly, in the case of RA, an allele of $M E F V$ that is thought to cause less severe FMF, the E148Q mutation, was predominantly present in the carrier cohort. Because E148Q is common among Semites, Punjabi Indians, and Chinese, ${ }^{24}{ }^{33}{ }^{36}$ and therefore may be carried by millions, this mutation may affect patients with RA world wide.

It is plausible that patients carrying an $M E F V$ mutation may benefit from colchicine, the mainstay drug of FMF treatment, yet careful assessment is warranted because the mode of action of colchicine is still not well understood. For instance, despite an apparent increase in IL1 $\beta$ expression and synthesis, ${ }^{45}$ the anti-inflammatory action of the drug may be related to an up stream inhibition of leucocyte migration to the synovium. Colchicine has been shown to exert a favourable effect on osteoarthritis in Indian patients. ${ }^{46}$ Intervention using this drug in RA is currently rare and is limited to certain extra-articular manifestations such as amyloidosis, ${ }^{47}$ nodulosis, ${ }^{48}$ or pericarditis. ${ }^{49}$

Two observations reported herein suggest that FMF mutations are not positively associated with a predisposition to develop RA. Firstly, patients with RA have a mutation frequency similar to that of control subjects, suggesting that the mutation carriers would not have an increased risk of developing RA. Secondly, a trend towards late age at onset in the carrier group of this study suggests that the contribution of the $M E F V$ mutations toward triggering RA is relatively weak, or even protective. It is also of note that despite autosomal inheritance of the $M E F V$ gene, and contrary to former studies, ${ }^{33} 36$ all mutation carriers in this study were women. The absence of male carriers may be attributed to the small male group $(\mathrm{n}=24)$. Nevertheless, RA may occur more readily in female carriers as the susceptibility of women to RA might reflect sensitivity also to non-sex related genetic factors. ${ }^{50}$ Studies of larger cohorts would be better able to examine this issue of sex bias.

In conclusion, the results reported herein support the hypothesis that patients with RA carrying one $M E F V$ mutation seem to be highly susceptible to developing a severe disease. Moreover, these data suggest that $M E F V$ mutations may increase the risk of developing RA in women. These and similar data and the proposed mode of action suggest a modifier role for pyrin in RA and in a wide spectrum of autoinflammatory and autoimmune diseases. Mutations in $M E F V$ that are known to cause FMF may therefore be prognostic for autoimmune disease outcome.

\section{Authors' affiliations}

E Rabinovich, A Livneh, P Langevitz, N Brezniak, M Pras, Y Shinar, Heller Institute of Medical Research, Sheba Medical Centre and Tel Aviv University, Tel Hashomer, Israel

E Shinar, MDA National Blood Services, Tel Hashomer, Israel

This study was approved by the institutional ethical committee at the Sheba Medical Centre.

\section{REFERENCES}

1 Stastny P. Association of the B-cell alloantigen DRw4 with rheumatoid arthritis. N Engl J Med 1978;298:869-71.

2 Ollier W, Thomson W. Population genetics of rheumatoid arthritis. Rheum Dis Clin North Am, 1992;18:741-59.

3 Moxley G, Cohen HJ. Genetic studies, clinical heterogeneity, and disease outcome studies in rheumatoid arthritis. Rheum Dis Clin North Am 2002;28:39-58.

4 Jawaheer D, Seldin MF, Amos Cl, Chen WW, Shigeta R, Etzel C, et al. Screening the genome for rheumatoid arthritis susceptibility genes: a replication study and combined analysis of 512 multicase families. Arthritis Rheum 2003;48:906-16.

5 Fisher SA, Lanchbury JS, Lewis CM. Meta-analysis of four rheumatoid arthritis genome-wide linkage studies: confirmation of a susceptibility locus on chromosome 16. Arthritis Rheum 2003;48:1200-6.

6 Eyre S, Barton A, Shephard N, Hinks A, Brintnell W, MacKay K, et al. Investigation of susceptibility loci identified in the UK rheumatoid arthritis whole genome scan in a further series of 217 UK affected sibling pairs. Arthritis Rheum 2004;50:729-35.

7 Larsen A, Thoen J. Hand radiography of 200 patients with rheumatoid arthritis repeated after an interval of one year. Scand J Rheumatol 1987; 16:395-401.

8 Orces CH, Del Rincon I, Abel MP, Escalante A. The number of deformed joints as a surrogate measure of damage in rheumatoid arthritis. Arthritis Rheum 2002;47:67-72.

9 Weyand CM, Hicok KC, Conn DL, Goronzy JJ. The influence of HLA DRB 1 genes on disease severity in rheuamatoid arthritis. Ann Intern Med 1992;117:801-6.

10 Jacoby RK, Jayson MI, Cosh JA. Onset, early stages, and prognosis of rheumatoid arthritis: a clinical study of 100 patients with 11-year follow-up. BMJ 1973;2:96-100.

11 Bukhari M, Lunt M, Harrison BJ, Scott DGI, Symmons DPM, Silman AJ. Rheumatoid factor is the major predictor of increasing severity of radiographic erosions in rheumatoid arthritis: results from the Norfolk Arthritis Register Study, a large inception cohort. Arthritis Rheum 2002;46:906-12.

12 Buchs N, di Giovani FS, Silverstri T, Vannier F, Duff GW, Miossec R. IL-1B and IL-1Ra polymorphisms and disease severity in rheumatoid arthritis: interaction with their plasma levels. Genes Immun $2001 ; 2: 222-8$. 
13 Morgan AW, Griffiths B, Ponchel F, Montague BM, Ali M, Gardner PP, et al. Fcgamma receptor type IIIA is associated with rheumatoid arthritis in two distinct ethnic groups. Arthritis Rheum 2000;46:556-9.

14 Rodrigeuz MR, Gonzalez-Escribano MF, Aguilar F, Velenzuela A, Garcia A, Nunez-Roldan A. Association of NRAMP1 promoter gene polymorphism with the susceptibility and radiological severity of rheumatoid arthritis. Tissue Antigens 2002;59:311-15.

15 Gumucio DL, Diaz A, Schaner P, Richards N, Babcock C, Schaller M, et al. Fire and ICE: the role of pyrin domain-containing proteins in inflammation and apoptosis. Clin Exp Rheumatol 2000;20(suppl 26):S45-53.

16 International FMF Consortium. Ancient missense mutations in a new member of the RoRet gene family are likely to cause familial Mediterranean fever. Cell 1997:90:797-807.

17 French consortium. A candidate gene for familial Mediterranean fever. Nat Genet 1997; 17:25-31

18 Ozdogan H, Arisoy N, Kasapcapur O, Sever L, Caliskan S, Tuzuner N, et al. Vasculitis in familial Mediterranean fever. J Rheumatol 1997;24:323-7.

19 Cattan D, Notarnicola C, Molinari N, Touitou I. Inflammatory bowel disease in non-Ashkenazi Jews with familial Mediterranean fever. Lancet 2000;355:378-9.

20 Touitou I, Magne X, Molinari N, Navarro A, Quellec AL, Pico P, et al. MEFV mutations in Behçet's disease. Hum Mutation 2000;16:271-2.

21 Livneh A, Aksentijevich I, Langevitz P, Torosyan Y, G-Shoham N, Shinar Y, et al. A single mutated MEFV allele in Israeli patients suffering from familial Mediterranean fever and Behçet's disease (FMF-BD). Eur J Hum Genet 2001;9:191-6.

22 Gershoni-Baruch R, Broza Y, Brik R. Prevalence and significance of mutations in the familial Mediterranean fever gene in Henoch-Schonlein purpura. J Pediatr 2003:43:658-61.

23 Shinar Y, Livneh A. Villa Y, Pinhasov A, Zeitoun I, Kogan A, et al. Common mutations in the Mediterranean fever gene associate with rapid progression to disability in non-Ashekanazi Jewish multiple sclerosis patients. Genes Immun 2003;4:197-203.

24 Booth DR, Lachmann HJ, Gillmore JD, Booth SE, Hawkins PN. Prevalence and significance of the familial Mediterranean fever gene encoding pyrin Q148. QJM 2001;94:527-31.

25 Ozen S, Bakkaloglu A, Yilmaz E, Duzuva A, Balci B, Topaloglu R, et al. Mutations in the gene for familial Mediterranean fever: do they predispose to inflammation? J Rheumatol 2003;30:2014-18

26 Heller H, Gafni J, Michaeli D, Shahin N, Sohar E, Erlich G, et al. The arthritis of familial Mediterranean fever. Arthritis Rheum 1966;9:1-17.

27 Dewalle M, Domingo C, Rozenbaum M, Ben-Chetrit E, Cattan D, Bernot A, et al. Phenotype-genotype correlation in Jewish patients suffering from familial Mediterranean fever (FMF). Eur J Hum Genet 1998;6:95-7.

28 Cazeneuve C, Sarkisian T, Pecheux C, Dervichian M, Nedelec B, Reiner P, et al. MEFV gene analysis in Armenian patients with familial Mediterranean fever: diagnostic value and unfavorable renal prognosis of the M694V homozygous genotype-genetic and therapeutic implications. Am J Hum Genet 1999;65:88-97.

29 Shinar Y, Livneh A, Langevitz P, Zaks N, Aksentijevich I, Kozoil DE, et al. Genotype-phenotype assessment of common genotypes among patients with familial Mediterranean fever patients. J Rheumatol 2000;27:1703-7.

30 Brik R, Shinawi M, Kasinetz L, Gershoni-Baruch R. The musculoskeletal manifestations of familial Mediterranean fever in children genetically diagnosed with the disease. Arthritis Rheum 2001:44:1416-19.

31 Centola M, Wood G, Frucht DM, Galon J, Aringer M, Farell C, et al. The gene for familial Mediterranean fever is expressed in early leukocyte development and regulated in response to inflammatory mediators. Blood 2000;95:3223-31.
32 Matzner Y, Abedat S, Shapiro E, Eisenberg S, Bar-Gil-Shitrit A, Stepensky P, et al. Expression of the Mediterranean fever gene and activity of the $\mathrm{C} 5 \mathrm{c}$ inhibitor in human primary fibroblast cultures. Blood 2000;96:727-31.

33 Stoffman N, Magal N, Shohat T, Lotan R, Koman S, Oron A, et al. Higher than expected carrier rate for familial Mediterranean fever in various Jewish ethnic groups. Eur J Hum Genet 2000;8:307-10.

34 Tsuchiya N, Ohashi J, Tokunaga K. Variations in immune response genes and their associations with multifactorial immune disorders. Immunol Rev 2002;190:169-81

35 Arnett FC, Edworthy SM, Bloch DA, McShane DJ, Fries JF, Cooper NS, et al. The American Rheumatism Association 1987 revised criteria for the classification of rheumatoid arthritis. Arthritis Rheum 1988;31:315-24.

36 Kogan A, Shinar Y, Lidar M, Revivo A, Langevitz P, Padeh S, et al. Common MEFV mutations among Jewish ethnic groups in Israel: high frequency of carrier and phenotype III states and absence of a perceptible biological advantage for the carrier state. Am J Med Genet 2001;102:272-6.

37 Pras E, Aksentijevich I, Gruberg L, Balow JE Jr, Prosnen L, Dean M, et al. Mapping of a gene causing familial Mediterranean fever to the short arm of chromosome 16. New Engl J Med 1992;326:1509-13.

38 Martinon F, Hofmann K, Tschopp J. The pyrin domain: a possible member of the death domain-fold family implicated in apoptosis and inflammation. Curr Biol 2001;11:R118-20.

39 Richards N, Schaner P, Diaz A, Stuckey J, Shelden E, Nadhwa A, et al. Interaction between pyrin and the apoptotic speck protein (ASC) modulates ASC-induced apoptosis. J Biol Chem 2001;276:39320-9.

40 Srinivasula SM, Poyet JL, Razmara M, Datta P, Zhang Z, Alnemri ES. The PYRIN-CARD protein ASC is an activating adaptor for caspase-1. J Biol Chem 2002;277:21119-22.

41 Chae JJ, Komarow HD, Cheng J, Wood G, Raben N, Liu PP, et al Targeted disruption of pyrin, the FMF protein, causes heightened sensitivity to endotoxin and a defect in macrophage apoptosis. Mol Cell 2003;11:591-604.

42 Dayer JM. The pivotal role of interleukin-1 in the clinical manifestations of rheumatoid arthritis. Rheumatology (Oxford), 2003;42(suppl 12):ii3-10.

43 Kary S, Burmester GR. Anakinra: the first interleukin-1 inhibitor in the treatment of rheumatoid arthritis. Int J Clin Pract 2003;57:231-4.

44 Tunca M, Kirkali G, Soyłurk M, Akar S, Pepys MB, Hawkins PN. Acute phase response and evolution of familial Mediterranean fever. Lancet 1999;353:1415.

45 Manie S, Schmid-Alliana A, Kubar J, Ferrua B, Rossi B. Disruption of microtubule network in human monocytes induces expression of interleukin-1 but not that of interleukin-6 nor tumor necrosis factor-alpha. Involvement of protein kinase A stimulation. J Biol Chem 1993;268:13675-81.

46 Das SK, Mishra K, Ramakrishnan S, Srivastava R, Agarwal GG, Singh R, et al. A randomized controlled trial to evaluate the slow-acting symptom modifying effects of a regimen containing colchicine in a subset of patients with osteoarthritis of the knee. Osteoarthritis Cartilage 2002;10:247-52.

47 Kanevskaia MZ, Chichasova NV, Varshavskii VA, Krel' AA. [The potentials of colchicine in the combined therapy of secondary amyloidosis in patients with rheumatoid arthritis. ] Ter Arkh, 1991;63:93-7.

48 Abraham Z, Rozenbaum M, Rosner I. Colchicine therapy for low-dosemethotrexate-induced accelerated nodulosis in a rheumatoid arthritis patient. Dermatology 1999;26:691-4.

49 Finkelstein Y, Shemesh J, Mahlab K, Abramov D, Bar-El Y, Sagie A, Sharoni $\mathrm{E}$, et al. Colchicine for the prevention of postpericardiotomy syndrome. Herz 2002;27:791-4.

50 Vandenbroeck K, Cunningham S, Goris A, Alloza I, Heggarty S, Graham C, et al. Polymorphisms in the interferon-gamma/interleukin-26 gene region contribute to sex bias in susceptibility to rheumatoid arthritis. Artritis Rheum 2003:48:2773-8 